\title{
CJID: Volume 3
}

$\mathrm{W}$ ELCOME TO THE THIRD VOLUME OF THE CANADIAN Journal of Infectious Diseases. The first two years of publication have established the Journal, and as we enter our third year readers will note some changes. It seems appropriate to review the activities of the journal for the past two years, and discuss current goals and new initiatives.

The stated goals in the inaugural issue of 1990 were "to develop a high calibre scientific journal which publishes original research relating to all aspects of infectious diseases..." and to "develop as a focus and a forum for publication and discussion of items of relevance to infectious diseases in Canada" (1). How well have we achieved these goals? The initial seven issues included 27 scientific articles including reviews, nine case reports, and two symposia. Thirteen, or almost $50 \%$ of the original articles and reviews had a Canadian focus. In addition, the two symposia provided papers from a Canadian symposium discussing infection and immunity in human immunodeficiency virus infection (2), and discussion papers and summary of the Consensus Conference on Lyme disease, dealing with uniquely Canadian aspects of this disease (3). Six LCDC reports have provided insights into the activities of this government bureau, a central player in infectious diseases in Canada, and one independent supplement has been published summarizing a symposium examining Canadian implications of universal hepatitis B vaccination (4). This record documents that the goals of publishing scientifically valid papers with a unique but not exclusively - Canadian focus have been met in the first two volumes.

How do we expand on this strong and successful beginning to continue to achieve our objectives and ensure that the Journal provides a service to the Canadian constituency? One focus is to increase the profile of the Journal both inside and outside Canada. The initiation and presence of the Journal has been widely advertised through our publishers and the Journal is currently subscribed to by a number of institutions. Current paid subscriptions are $70 \%$ Canadian, $21 \%$ American and 9\% international. In addition, 10 to $20 \%$ of current manuscript submissions are from outside Canada. Thus, we are establishing a presence beyond our borders. In the upcoming year we plan to establish an international advisory board to assist us in defining the Journal's direction, particularly with respect to issues outside Canada.

Another initiative - starting with this issue - is the 'Infectious Disease notes', both pediatric and adult. These pages will provide informal insights into current developments and controversies in infectious diseases. The coordinators of the 'notes' welcome comments or questions from readers dealing with any aspects of infectious diseases.

In 1992 the frequency of the Journal will increase the from four to six issues in each volume. This increase in frequency reflects the stability of the Journal and the success in our initial two years, and will partially resolve concerns that quarterly publication does not allow us to provide information at the frequency that we would wish. The increased frequency of publication is, of course, one element in increasing the profile of the Journal. It also reflects the number and quality of submissions being received and our desire to publish accepted manuscripts expeditiously.

As we move into our third year, then, we can look back at two successful founding years, and look forward to continued development of The Canadian Journal of Infectious Diseases. The contributions of many individuals including the editorial board, authors, reviewers across Canada and from other countries, and publishers and advertisers need to be acknowledged. We are clearly developing as we move into our third year, although a number of initiatives remain to be pursued. As suggested in the initial editorial of our premier issue, we welcome letters, questions or comments from any of our readers to assist us in determining whether the Journal is meeting its goals as well as giving us some guidance for future directions.

\section{REFERENCES}

1. Nicolle LE. New journal for the '90s. Can J Infect Dis $1990 ; 1: 1-2$.

2. Infection and Immunity Symposium. Can $J$ Infect Dis 1991:2:4-36.

3. Laboratory Centre for Disease Control Consensus Conference on Lyme Disease. Can J Infect Dis 1991:2:49-70.

4. Hepatitis B: Canada's overlooked STD. Implications for heath care policy. Can J Infect Dis 1991;2 (Suppl A):1A-37A.

LE Nicolle, MD Editor-in-Chief Winnipeg, Manitoba 


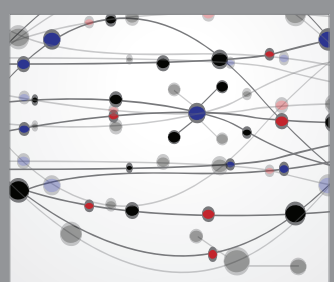

The Scientific World Journal
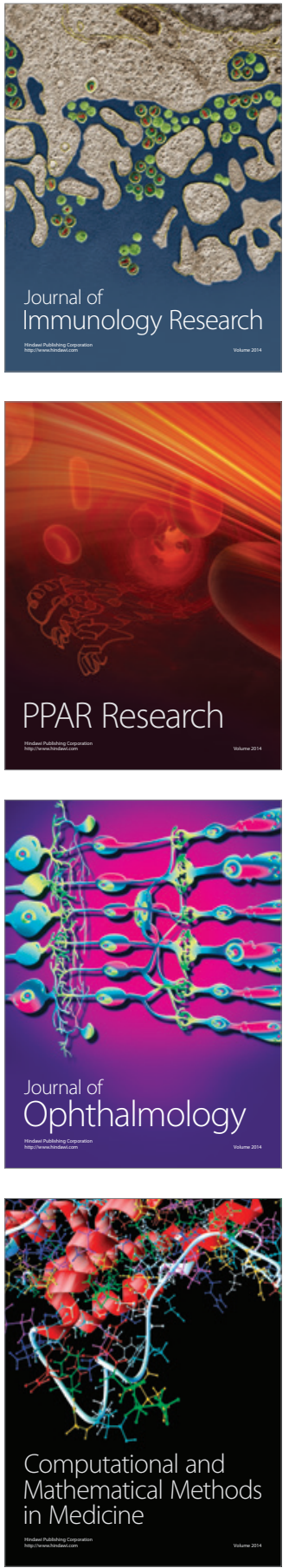

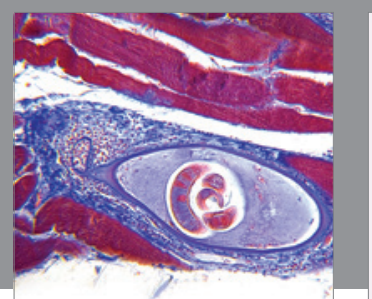

Gastroenterology Research and Practice

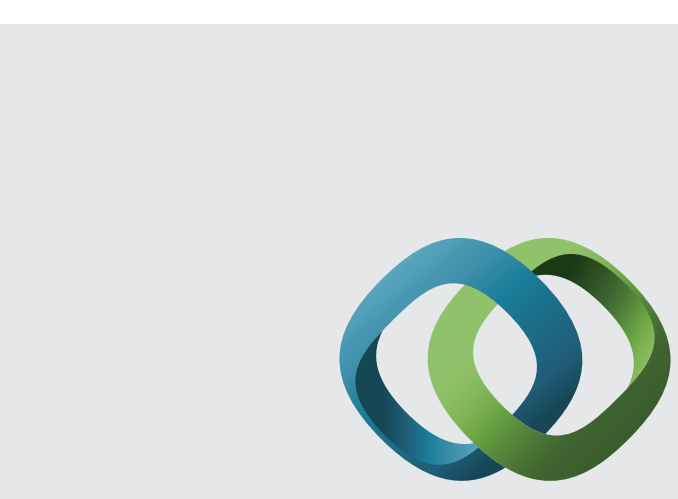

\section{Hindawi}

Submit your manuscripts at

http://www.hindawi.com
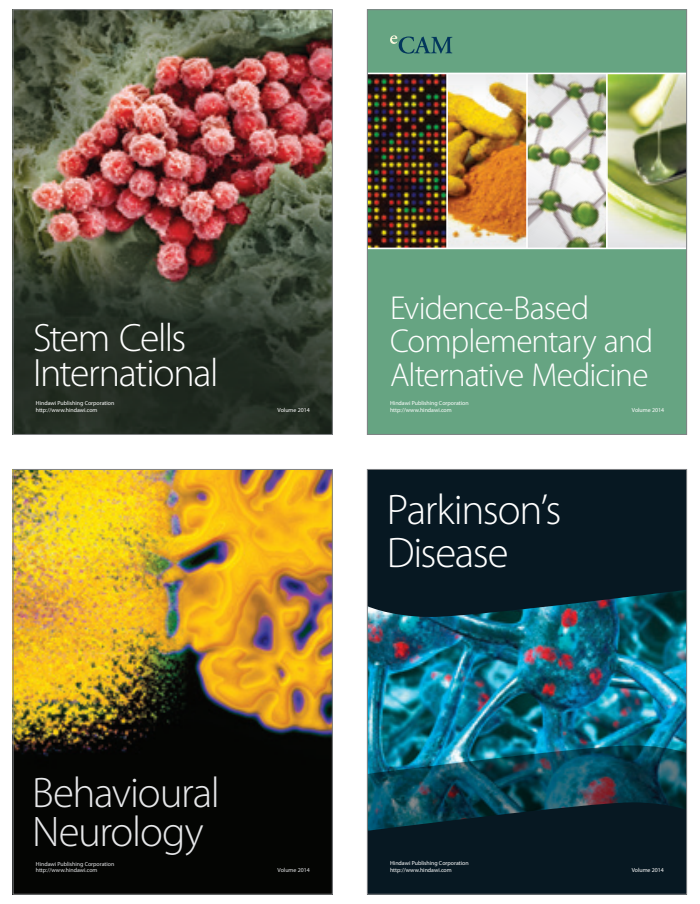
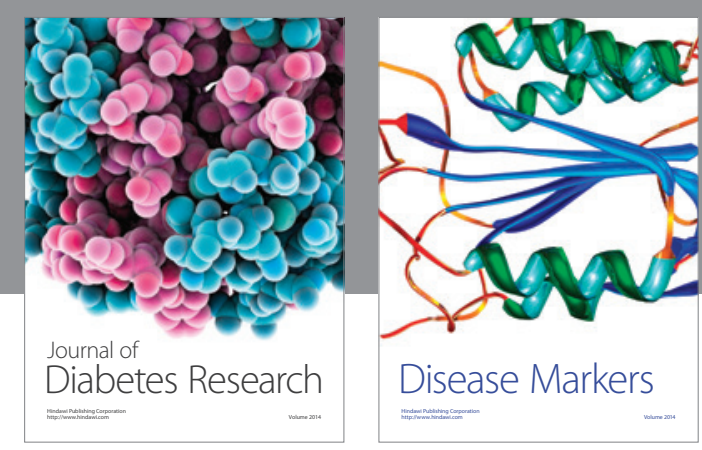

Disease Markers
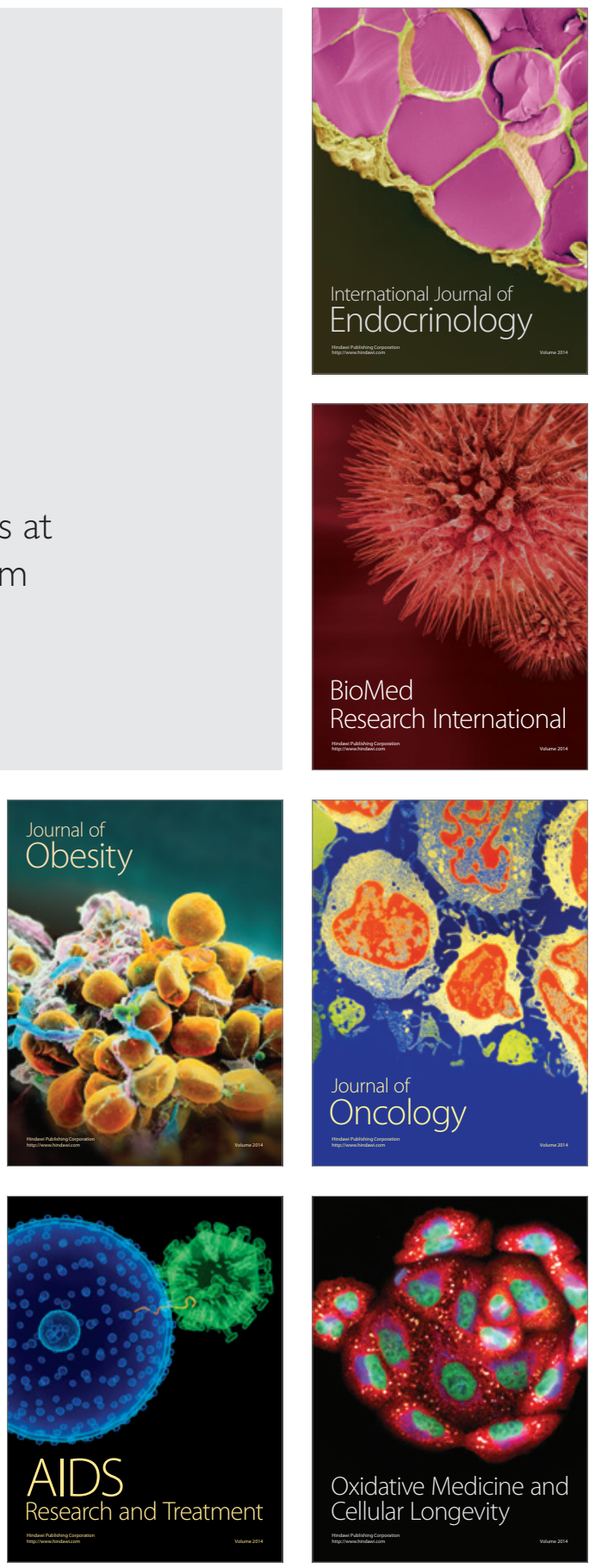